\title{
86270 - A CONTRIBUIÇÃO DOS LAUDOS PERICIAIS DO ASSISTENTE SOCIAL NA ELABORAÇÃO DAS SENTENÇAS DE PROCESSOS JUDICIAIS DO BENEFÍCIO DE PRESTAÇÃO CONTINUADA/IDOSO
}

\author{
Pôster - Gerontologia
}

Lisete Maria Pozatti / Lisete Maria Pozatti / UFRGS - Mestrado em Política Social e Serviço Social; Sergio Antonio Carlos / Sergio Antonio Carlos / UFRGS - PPG em Política Social e Serviço Social

Introdução: Fundamentando-se na legislação e no trabalho dos assistentes sociais peritos judiciais, a partir da experiência da primeira autora, busca-se aprofundar os laudos e sentenças dos processos de idosos requerentes do Benefício de Prestação Continuada (BPC) que tramitaram no Tribunal Regional Federal da 4 a Região (TRF4-RS) com sentenças proferidas em 2017. Objetivo: Identificar a contribuição do laudo pericial dos assistentes sociais nas sentenças proferidas pelos juízes de processos BPC/idoso. Metodologia: Foi realizada uma pesquisa qualitativa a partir da análise de 79 processos com sentença proferida em 2017 e que continham laudo do perito assistente social. O uso destes processos foi autorizado pelo TRF4-RS e aprovado pelo Comitê de Ética do Instituto de Psicologia da UFRGS sob n⿳02762730/2018. Os laudos e sentenças foram analisados utilizando-se software de apoio à análise de dados qualitativos (computer assisted qualitative data analysis software - CAQDAS), o programa NVivo12. Para instrumentalizar a análise, foram utilizados os recursos de contagem de palavras e construção de árvore de palavras. Resultados: Identificamos uma variedade de concepções empregadas na construção do documento pericial e uma efetiva contribuição dos laudos sociais nas sentenças. Comparando-se aos dados de renda per capita final, miserabilidade (comprovada ou não) dos 79 processos com a sentença proferida, observa-se que a judicialização do BPC apresenta diversidade tanto nos critérios objetivos quanto nos critérios subjetivos utilizados pelos profissionais envolvidos. Conclusão: Conclui-se que a renda, como critério objetivo, não é determinante para o resultado sentencial. Entretanto, a comprovação de miserabilidade se mostrou um fator relevante na decisão da sentença para concessão do BPC. Da mesma forma, com base nos conteúdos dos laudos periciais foi possível inferir a consideração da condição habitacional nas decisões. É possível destacar a relevância e efetiva contribuição do laudo de perícia social, para a decisão do magistrado. Para tal faz-se necessária maior qualificação dos profissionais assistentes sociais na elaboração de perícia.

Palavras-chave: Idoso, Perícia Social, Judicialização do BPC. 